allowed poorer, countries, mainly Middle Eastern, African and South Asian, to host the vast majority of refugees. Their initiative should involve setting up strong refugee systems: allowing people to apply for asylum, treating their refugee claims fairly, resettling the most vulnerable of all and providing basics like education and healthcare.

In the words of Martin Luther King:

Injustice anywhere is a threat to justice everywhere. We are caught in an inescapable network of mutuality, tied in a single garment of destiny. Whatever affects one directly, affects all indirectly.

The Syrian catastrophe is a failure of humanity and the need for action is now. Syria was the cradle of civilisation and should not become its grave.

\section{References}

Abbara, A., Coutts, A., Fouad, M. F., et al (2016) Mental health among displaced Syrians: findings from the Syria Public Health Network. Journal of the Royal Society of Medicine, 109(3), 88-90.

Abou-Saleh, M. T. \& Hughes, P. (2015) Mental health of Syrian refugees: looking backwards and forwards. Lancet Psychiatry, 2, 870-871.

Akl, E. A., El-Jardali, F., Bou Karroum, L., et al (2015) Effectiveness of mechanisms and models of coordination between organizations, agencies and bodies providing or financing health services in humanitarian crises: a systematic review. PLoS One, 10(9), e0137159.

Bogic, M., Njoku, A. \& Priebe, S. (2015) Long-term mental health of war-refugees: a systematic literature review. BMC International Health and Human Rights, 15, 29.
MSF (2015) Syria 2015: Documenting War-Wounded and War-Dead in MSF-Supported Medical Facilities in Syria. Available at https:// www.doctorswithoutborders.org/sites/usa/files/syria_2015 wardead_and_war-wounded_report_en.pdf (accessed 1 September 2016).

Siriwardhana, C., Abas, M., Siribaddana, S., et al (2015) Dynamics of resilience in forced migration: a 1-year follow-up study of longitudinal associations with mental health in a conflict-affected, ethnic Muslim population. BMJ Open, 5(2), e006000.

Society of Preventive Psychiatry (2016) Anti-war Declaration of Athens. Available at http://www.psychiatricprevention.com (accessed 1 September 2016).

Tol, W. A., Barbui, C., Galappatti, A., et al (2011) Mental health and psychosocial support in humanitarian settings: linking practice and research. Lancet, 378, 1581-1591.

UNHCR (2013) Mental Health and Psychosocial Support for Persons of Concern. Available at http://www.unhcr.org/51bec3359.pdf (accessed 1 September 2016).

UNHCR (2015) Global trends. At http://www.unhcr.org/en-us/ statistics/unhcrstats/576408cd7/unhcr-global-trends-2015.html (accessed 1 September 2016).

UNICEF (2012) Syria's Children: A Lost Generation? Available at http://www.unicef.org.hk/upload/NewsMedia/publication/ Syria_2yr_Report.pdf (accessed 1 September 2016).

WFMH (2013) People's Charter for Mental Health. Available at http://staging.wfmh.com/wp-content/uploads/2014/02/THEPEOPLES-CHARTER-2013.pdf (accessed 1 September 2016).

WHO (2015) mhGAP Humanitarian Intervention Guide (mhGAP. HIG) Available at http://www who.int/mental_health/publications/ mhgap_hig/en (accessed 1 September 2016).

World Psychiatric Association (2016) Position Statement on Europe's Migrant and Refugee Crisis. WPA.

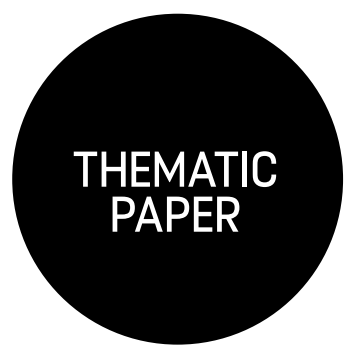

\title{
Mental health and psychosocial needs of Syrian refugees and the role of Syrian non-governmental organisations
}

\author{
Nadim Almoshmosh, ${ }^{1}$ Mamoun Mobayed ${ }^{2}$ and Mohammad Aljendi ${ }^{3}$
}

${ }^{1}$ Consultant Psychiatrist, Global Medics, UK, emal nalmoshmosh@gmail. ${ }^{2}$ Consultant Psychiatrist, Behavioral Healthcare Center in Doha, Qatar

${ }^{3}$ Consultant Psychiatrist, Al Amal Complex for Mental Health, Jeddah, Saudi Arabia

Declaration of interest: All authors work closely with Syrian refugees and are members of the Syrian Association for Mental Health (SAMH).
Almost 5 million Syrians have been registered as refugees since the conflict started in 2011. Their mental health and psychosocial needs continue to grow as the situation at home gets more complicated. Syrian nongovernmental organisations (NGOs) and mental health professionals have been offering their support to help meet these needs. They have set up various centres and teams on the ground that focus their efforts on the most needy individuals. They train and supervise healthcare volunteers, encourage self-management and build on people's resilience. These NGOs require support to deal with the consequences of this unprecedented crisis.
Civil demonstrations that began in March 2011 were met with force which escalated into a civil war that now is in its sixth year. Millions of Syrians, almost half the Syrian population, have been displaced either internally or as refugees in neighbouring countries and beyond. The number of registered refugees recorded by the Office of the United Nations High Commissioner for Refugees (UNHCR) now stands at 4.8 million, with just under half a million of these being resident in camps (data from the UNHCR portal, http://data. unhcr.org, August 2016). As is often the case in armed conflicts, civilians are the main victims, and we highlight here their mental health and psychosocial needs along with the response from Syrian non-governmental organisations (NGOs). 


\section{Mental health of Syrian refugees}

Syrians have experienced the consequences of this conflict on an unprecedented scale. Loss and grief for missing or deceased relatives are at the centre of this, along with material losses. Ongoing concerns about the safety of family members are reported to be a significant source of stress (United Nations Children's Fund \& International Medical Corps, 2014).

Attending to mental health needs in this part of the world is often neglected and below standard at the best of times, let alone at a time of an immense crisis like this. The stigma of mental illness in Syrian society is high, which often results in a delay in assessments and hindrance to follow-up for those who have mustered the courage to be seen in the first instance (Almoshmosh, 2015). Screening for problems in this geographically scattered population requires resources, local knowledge, availability of personnel and, most importantly, the affected people being willing to talk about their mental health needs. It is difficult to obtain an accurate indication of these needs given the above variables and also considering the frequent movement of these populations.

Studies of the mental health needs of Syrian refugees have mostly been surveys and crosssectional evaluations in camps or in small communities (e.g. schools). These generally suggest a rising level of psychosocial distress.

A wide range of mental health problems exist, including exacerbations of pre-existing mental disorders, new problems caused by conflict-related violence, displacement and multiple losses, as well as issues related to adaptation to new settings (Hassan et al, 2015). Symptoms reported in adults include sadness, grief, fear, frustration, anxiety, anger and despair. Cognitive manifestations include loss of control, helplessness, boredom as well as physical symptoms such as fatigue, loss of appetite and medically unexplained physical complaints. There is limited information on Syrian refugees with psychosis or other severe mental disorders.

Surveys of Syrian refugee children have revealed a range of psychosocial problems (Cartwright $e t$ al, 2015), including persistent fears and anxiety, sadness, aggression, bedwetting, speech problems and somatic symptoms. One has to be cautious about the outcome of studies that use non-diagnostic tools, as they are often done in challenging environments and with emotionally charged samples. The high prevalence rates of post-traumatic stress disorder (PTSD) in some of these studies, such as the survey by Vukcevic et al (2014), are hard to justify, as they are done in asylum centres, often after participants' lengthy transfer journeys, with no follow-up studies to review progress or stability of cases. It is also hard to generalise the results of such studies as representative samples are difficult to achieve. The tools used have not been validated for use on Syrians in the current context of this conflict (Wells et al, 2015). A narrow focus on the effects of past events in Syria may lead to a conflation of the symptoms of PTSD or clinical depression with distress generated by stressors related to the postdisplacement context (Miller \& Rasmussen, 2014).

\section{Syrian non-governmental organisations}

The historical shortage of mental health services in the area has exacerbated the gap between the increased demands and the provision of mental health and psychosocial support services. This has prompted many expatriate Syrian mental health professionals to volunteer their expertise to help cover some of the psychosocial needs of Syrians. Various Syrian NGOs and groups have been established and registered in neighbouring countries. These are mostly self-run, though with some involvement from local authorities and links with other humanitarian agencies.

A group of Syrian psychiatrists and psychologists formed the Syrian Association for Mental Health (SAMH) to coordinate their efforts. The aim is to promote better mental healthcare and psychosocial support for Syrians. Most of this effort so far has mainly been to help Syrian refugees in neighbouring countries. This is fraught with difficulty, as there are various obstacles to Syrian professionals seeking to obtain a licence to practise in these countries. It has been unsafe for members of SAMH to operate inside Syria, although support and some supervision for mental health professionals have been possible using information technology. SAMH has been providing training workshops for Syrian mental health workers and volunteers, as well as support and advice for existing professionals inside Syria and the refugee camps. Two centres run by SAMH are now established in southern Turkey that provide psychosocial support and counselling for affected Syrian refugees. SAMH has also been organising an annual conference in Gaziantep, Turkey, since 2012. The conference usually has an accompanying programme running over 2 weeks that offers training workshops and support for volunteers.

The Union of Syrian Medical Care and Relief Organisations (UOSSM) has launched a Psychological Care Programme to reduce the impact of the conflict on Syrian people. It has established mental health and psychosocial support services in Syria, Turkey and Lebanon. Care and psychosocial support have been provided to populations in schools, camps, care homes and rehabilitation centres, totalling more than 50000 refugees and internally displaced Syrians. UOSSM also provides telepsychiatry services in coordination with Syrian doctors from Yale University.

The Syrian American Medical Society (SAMS) collaborates with a team of psychologists, psychiatrists and psychosocial workers in Jordan to provide mental health rehabilitation to affected Syrians. The team offers services in a SAMS-run facility and they also visit families in their homes. Syrian families receive counselling as well as physical and psychosocial support. Some 12000 
people, many of them women and children, have been helped by these programmes.

Al-Sham humanitarian foundation and Balsam are charities that have centres in Gaziantep and Kilis in Turkey. They provide counselling, psychological support and rehabilitation for Syrian trauma survivors besides running other humanitarian projects and services for the Syrian community.

Many other individual initiatives are taking place to help support Syrian refugees. Visiting mental health professionals from around the world have also been offering support and training in coordination with Syrian NGOs or with other humanitarian agencies.

In coordination with Syrian charities and Syrian psychiatrists, the National Centre for Mental Health (NCMH) in Reyhanli, Turkey, as well as centres in Tripoli and Bekaa in Lebanon, have been established. These provide psychosocial support for affected Syrians, and work to improve resilience, to protect vulnerable groups and to provide specific support to schools. The centres work with families to give displaced populations better coping strategies, and to provide regular training and supervision for front-line staff.

\section{Community-based programmes for children}

As more than half of Syrian refugees are children under the age of 18 (data from the UNHCR portal, August 2016) there is a need to focus more effort on this group. The United Nations also estimates that half of child refugees were not enrolled in schools in mid-2015. These children are also at risk of a range of mental health issues resulting from their traumatic experiences (Sirin \& RogersSirin, 2015). Helping children to be at school and provide them with support can go a long way in alleviating some of their distress and in reducing potential future psychological problems.

Various community-based programmes have been developed to help meet some of the psychosocial needs of Syrian refugees and their children. Members of SAMH have been delivering and supervising training on teaching recovery techniques (TRT) in Jordan, Lebanon and Turkey to a large number of families, teachers and children. This technique is based on the Children and War Foundation's programme. The aim is not to 'cure' symptoms but rather to give children better coping strategies so that they feel more in control of their reactions, and so are able to benefit from the support of their families and the opportunities available in schools (Children and War Foundation, n.d.).

\section{Conclusion}

Syrian NGOs have been providing psychosocial support and promoting the recovery of Syrian refugees. Relief services have focused not only on immediate crisis management and identifying morbidities, but also on the promotion of recovery. Resilience and self-management of affected individuals and their communities are highlighted and need to be further strengthened. The efforts of these NGOs need to be encouraged and they need to be supported to conduct studies that further evaluate the psychological consequences of this unprecedented crisis and ways to remedy them. The task is huge and requires continuing coordination with other international and humanitarian agencies.

\section{References}

Almoshmosh, N. (2015) Highlighting the mental health needs of Syrian refugees. Intervention, 13, 178-181. doi: 10.1097/ WTF.0000000000000085.

Cartwright, K., El-Khani, A., Subryan, A., et al (2015) Establishing the feasibility of assessing the mental health of children displaced by the Syrian conflict. Global Mental Health, 2, e8.

Children and War Foundation (n.d.) Teaching recovery techniques. At http://www.childrenandwar.org/resources/teaching-recoverytechniques-trt (accessed March 2016).

Hassan, G., Kirmayer, L. J., Mekki-Berrada, A., et al (2015) Culture, Context and the Mental Health and Psychosocial Wellbeing of Syrians. UNHCR.

Miller, K. E. \& Rasmussen, A. (2014) War experiences, daily stressors, and mental health five years on: elaborations and future directions. Intervention, 12(S1), 33-42.

Sirin, S. R. \& Rogers-Sirin, L. (2015) The Educational and Mental Health Needs of Syrian Refugee Children. Migration Policy Institute. Available at http://www.migrationpolicy.org/research/educationaland-mental-health-needs-syrian-refugee-children (accessed March 2016).

United Nations Children's Fund \& International Medical Corps (2014) Mental Health Psychosocial and Child Protection for Syrian Adolescent Refugees in Jordan. IMC, UNICEF.

Vukcevic, M., Dobric, J. \& Puric, D. (2014) Psychological characteristics of asylum seekers from Syria. In Survey of the Mental Health of Asylum Seekers in Serbia. UNHCR Serbia.

Wells, R., Wells, D. \& Lawsin, C. (2015) Understanding psychological responses to trauma among refugees: the importance of measurement validity in cross-cultural settings. Journal and Proceedings of the Royal Society of New South Wales, 148 , 455-456.

\section{International Perspectives on Psychiatry in Restrictive Environments or under Restrictive Conditions}

BJPsych International is seeking to survey across the world the practice of psychiatry in restrictive settings and conditions (prisons, jails, on parole, conditional release and community treatment under legal provision) as well as coercive practices in the management of people with a mental illness, beyond psychiatry. The journal, therefore, is inviting authors to submit papers on national or regional aspects of one or more of the above areas, highlighting current practice, relevant data (or lack of the same), training and service needs and areas for future research. For further information, please contact the deputy editor, George Ikkos, at ipgi@rcpsych.ac.uk 